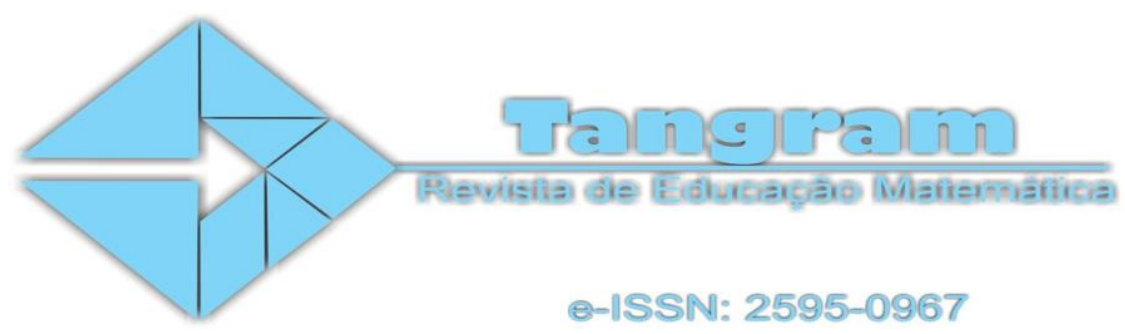

\title{
O Estágio Curricular Supervisionado e a formação do professor de Matemática: experiências em uma turma do Ensino Médio
}

\author{
The Supervised Internship and the formation of the Mathematics \\ teacher: experiences in a high school class
}

\section{La pasantía curricular supervisada y la formación del profesor de matemáticas: experiencias en una clase de secundaria}

\author{
Gevando Lopes Santos \\ Universidade do Estado da Bahia (UNEB), Campus VII \\ Senhor do Bonfim-BA, Brasil, \\ e-mail: gevandosantos95@gmail.com \\ orcid: 0000-0002-9908-8158 \\ Américo Junior Nunes da Silva \\ Universidade do Estado da Bahia (UNEB), Campus VII \\ Senhor do Bonfim-BA, Brasil, \\ e-mail: ajnunes@uneb.br \\ orcid: 0000-0002-7283-0367
}

Enviado:25/03/2020

Aceito:01/07/2020

DOI: 10.30612/tangram.v3i3.11291

\begin{abstract}
Resumo: O presente artigo objetiva relatar e refletir sobre as experiências vivenciadas durante o Estágio Curricular Supervisionado IV, do curso de Licenciatura em Matemática da Universidade do Estado da Bahia - UNEB, Campus VII - Senhor do Bonfim. O mesmo foi realizado durante o primeiro semestre de 2019 e buscou inserir o licenciando no espaço da docência em Matemática, em turmas do Ensino Médio, para que se vivenciassem situações que futuramente poderão ser encontradas no espaço de trabalho. Para isso foram realizadas as seguintes atividades: i) aproximação à realidade escolar por meio de leitura do Projeto Político Pedagógico, observação do espaço escolar e construção de projeto de intervenção; ii) docência em turma do Ensino Médio e iii) proposição de oficina. Vale salientar que o movimento de imersão na escola promoveu o desenvolvimento de conhecimentos necessários para o exercício da docência e contribuiu com o processo de constituição da identidade docente.
\end{abstract}

Palavras-chave: Estágio Supervisionado. Experiências. Ensino de Matemática.

Tangram - Revista de Educação Matemática, Dourados - MS - v.3 n.3, pp. 162 - 177 (2020)

Este obra está licenciada com uma Licença Creative Commons Atribuição-NãoComercial-CompartilhaIgual 3.0 Brasil. 


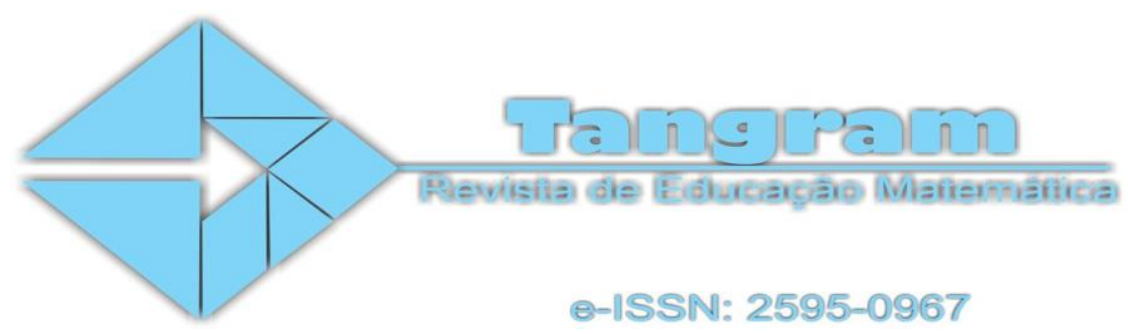

Abstract: This article aims to report and reflect on the experiences lived during the Supervised Internship IV, of the Mathematics Degree course at the State University of Bahia - UNEB, Campus VII - Senhor do Bonfim. The same was done during the first semester of 2019 and sought to insert the licensee in the teaching space in Mathematics, in high school classes, so that they could experience situations that in the future may be found in the workspace. For this, the following activities were carried out: i) approaching the school reality through reading the Political Pedagogical Project, observing the school space and building an intervention project; ii) teaching in a high school class and iii) proposing a workshop. It is worth mentioning that the immersion movement at school promoted the development of knowledge necessary for the exercise of teaching and contributed to the process of constituting the teaching identity.

Keywords: Supervised internship. Experiences. Mathematics teaching.

Resumen: Este artículo tiene como objetivo informar y reflexionar sobre las experiencias vividas durante la Pasantía Curricular Supervisada IV, del curso de Matemáticas en la Universidad Estatal de Bahía - UNEB, Campus VII - Senhor do Bonfim. Lo mismo se llevó a cabo durante el primer semestre de 2019 y buscó insertar al licenciatario en el espacio de enseñanza de Matemáticas, en las clases de secundaria, para que pudieran experimentar situaciones que en el futuro se puedan encontrar en el espacio de trabajo. Para ello, se llevaron a cabo las siguientes actividades: i) acercamiento a la realidad escolar a través de la lectura del Proyecto Pedagógico Político, observación del espacio escolar y construcción de un proyecto de intervención; ii) enseñar en una clase de secundaria y iii) proponer un taller. Vale la pena señalar que el movimiento de inmersión en la escuela promovió el desarrollo del conocimiento necesario para el ejercicio de la enseñanza y contribuyó al proceso de constitución de la identidad docente.

Palabras- chave: Prácticas supervisadas. Experiências. Enseñanza de las matemáticas.

\section{Introdução}

Sabe-se que em toda profissão os conhecimentos do conteúdo são fundamentais. Porém, eles por si só não são suficientes para tornar o indivíduo preparado para o exercício de sua profissão. É necessário que haja uma articulação entre diferentes conhecimentos e que isso seja percebido como indispensável para a profissionalização desse professor, como sinalizam Shulman (2005) e Pimenta e Lima (2006).

Escolhemos iniciar esse artigo por essa discussão, principalmente, por perceber nos cursos de Licenciatura em Matemática, como assevera Gatti (2010) e Gatti, Barreto, André

Tangram - Revista de Educação Matemática, Dourados - MS - v.3 n.3, pp. 162 - 177 (2020) 


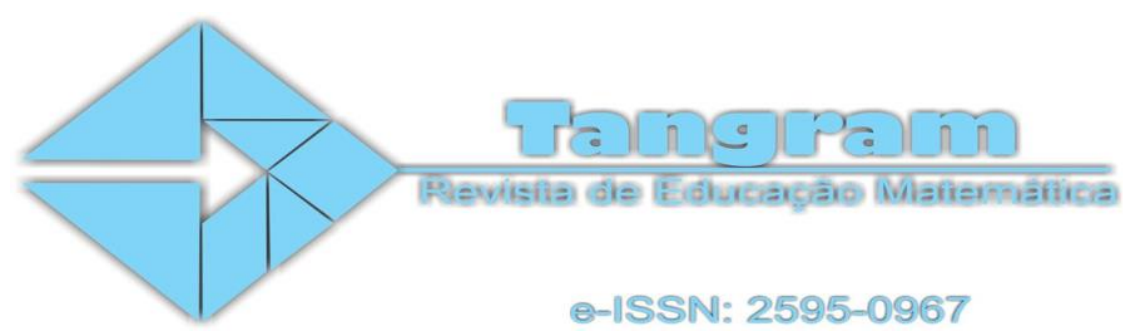

e Almeida (2019), uma supervalorização do conhecimento do conteúdo em detrimento dos conhecimentos pedagógico e do curriculum, por exemplo. Achamos oportuno começar por aqui, por percebermos o estágio enquanto espaço de formação em que essa articulação entre teoria e prática de fato acontece e onde esses diferentes conhecimentos necessários à docência precisam se articular com as diferentes realidades da educação básica.

O Estágio Curricular Supervisionado, como destacam Pimenta e Lima (2006), tem o intuito de inserir o licenciando no futuro espaço de trabalho, para que o mesmo possa vivenciar experiências e utilizar dos conhecimentos desenvolvidos ao longo da formação acadêmica para estabelecer a relação com a futura prática profissional. Dessa forma, o presente artigo objetiva relatar e refletir sobre as experiências vivenciadas durante o Estágio Supervisionado IV, do curso de Licenciatura em Matemática da Universidade do Estado da Bahia - UNEB, Campus VII - Senhor do Bonfim, Bahia.

O Estágio IV foi realizado no primeiro semestre de 2019, em um colégio da rede estadual de ensino da cidade de Senhor do Bonfim-BA, e buscou inserir o licenciando no espaço da docência em Matemática, em uma turma de terceiro ano do Ensino Médio, para que se vivenciassem situações que, provavelmente, serão encontradas no espaço de trabalho futuramente. Os conteúdos matemáticos previstos pelo professor supervisor foram ressignificados a partir da proposição de um projeto de intervenção que se fundamentou na resolução de situações-problema presentes no cotidiano e no preparo para o Exame Nacional do Ensino Médio (ENEM).

$\mathrm{Na}$ tentativa de apresentar coerentemente ao leitor as experiências vivenciadas e construir reflexões sobre elas, estruturamos este texto da seguinte forma: i) inicialmente abordaremos as características da turma e discutiremos sobre a participação do professor supervisor; ii) em seguida, após essa caracterização inicial, refletiremos sobre todas as experiências vivenciadas ao longo do estágio, desde a observação, planejamento e regência, até a realização de oficina; iii) por último teceremos algumas considerações sobre o trabalho realizado e os reflexos do mesmo para a formação e constituição da identidade docente.

Tangram - Revista de Educação Matemática, Dourados - MS - v.3 n.3, pp. 162 - 177 (2020) 


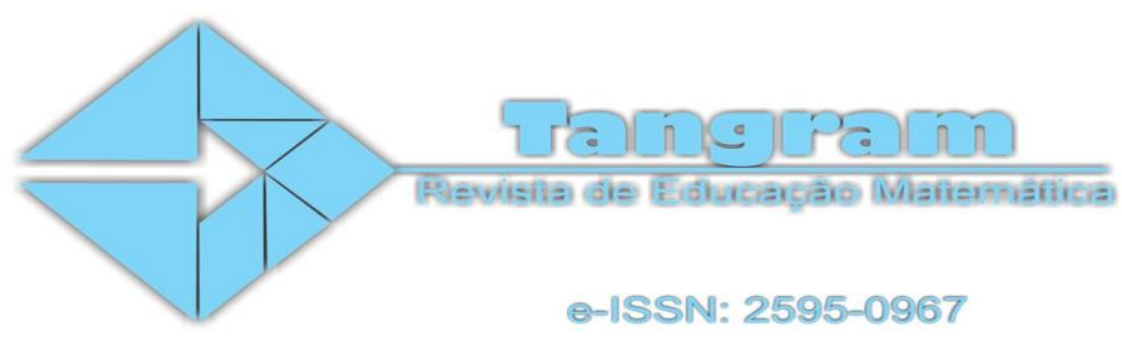

\section{Características da turma e a participação do professor supervisor}

Essa seção objetiva apresentar o perfil da turma e do professor supervisor, considerando a importância de o leitor deste texto conhecê-los, pois estiveram diretamente envolvidos em toda a experiência de estágio desenvolvida. Além disso, discutiremos, brevemente, sobre a importância de o professor supervisor participar de todo o estágio.

Em relação à turma: dos trinta e oito alunos matriculados, 15 eram do sexo masculino e 23 do sexo feminino. Possuíam, em média, de 16 a 18 anos e apresentavam bom comportamento, prestavam atenção nas aulas e participavam durante as explicações dos conteúdos e resolução dos exercícios.

Quanto ao professor supervisor: é licenciado em Matemática e Física pela Universidade do Estado da Bahia, professor concursado do estado da Bahia, com mais de vinte anos de serviço, e possui especialização na área de ensino de Matemática. Ao longo do estágio, durante as observações e realização da regência, mostrou-se preocupado com as questões de ensino e aprendizagem e apresentava estratégias diversas para promover a consolidação das habilidades matemáticas pelos estudantes.

Durante o período de estágio o professor supervisor esteve presente em todos os momentos e deu o suporte necessário para o desenvolvimento das atividades. Além dessas contribuições, o mesmo compartilhou experiências educacionais vividas dentro do ambiente escolar que proporcionaram a ampliação do conhecimento sobre a realidade dos alunos e da escola.

Para um bom desempenho durante a realização do estágio supervisionado, a participação do professor supervisor é importante, sobretudo pela experiência que o mesmo possui no ambiente educacional, visto que tem mais tempo de serviço na profissão. Nessa perspectiva, Scalabrin e Milionari (2013), ressaltam a importância do trabalho coletivo e do processo de troca de experiências. Isto porque o estágio se torna um sistema de cooperação, onde mesmo o professor supervisor tendo um maior conhecimento, no que se refere ao

Tangram - Revista de Educação Matemática, Dourados - MS - v.3 n.3, pp. 162 - 177 (2020) 


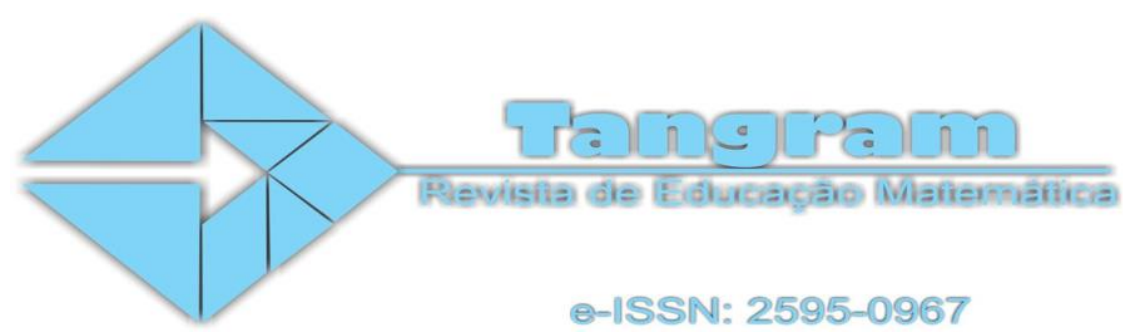

processo de ensino e aprendizagem, ele também aprende com o estagiário. Dessa forma, é a partir do conhecimento da realidade escolar e do compartilhamento de experiências com o professor supervisor, que o estagiário consegue desempenhar de uma melhor maneira a prática em sala de aula.

\section{Atividades desenvolvidas}

Para relatar e refletir sobre as experiências vivenciadas durante o estágio supervisionado, optamos por subdividir essa seção em subtópicos, considerando o processo formativo dessa experiência, bem como visando o melhor entendimento das etapas desse processo.

\section{Observação}

A atividade de observação é algo relevante durante o processo de estágio, como sinaliza Pimenta (2004), por situar o futuro professor no ambiente educacional, propiciar um conhecimento prévio sobre a realidade da sala de aula, bem como refletir as estratégias que o professor supervisor utiliza em suas aulas. Lembrando que essa observação extrapola, como assevera a autora, o imitar do que é observado. Trata-se de uma atividade reflexiva.

Nessa perspectiva, Zinke e Gomes (2015) ressaltam que a observação é uma etapa indispensável e uma ferramenta fundamental para relacionar a teoria com a prática, possibilitando que o futuro professor entre em contato com a realidade do ambiente educacional e a prática docente, fazendo um diagnóstico da mesma como forma de identificar as principais dificuldades, preparando-se melhor para exercer a futura profissão.

Após a reunião com a diretoria da unidade escolar, que nos apresentou o Projeto Político Pedagógico da Escola, e com o professor supervisor, iniciamos as atividades de observação, tanto da escola como da turma que realizaríamos o estágio. O conteúdo trabalhado pelo professor, no momento de observação, era Circunferência trigonométrica. Percebemos que o docente tinha uma boa relação com os discentes. A metodologia utilizada

Tangram - Revista de Educação Matemática, Dourados - MS - v.3 n.3, pp. 162 - 177 (2020) 


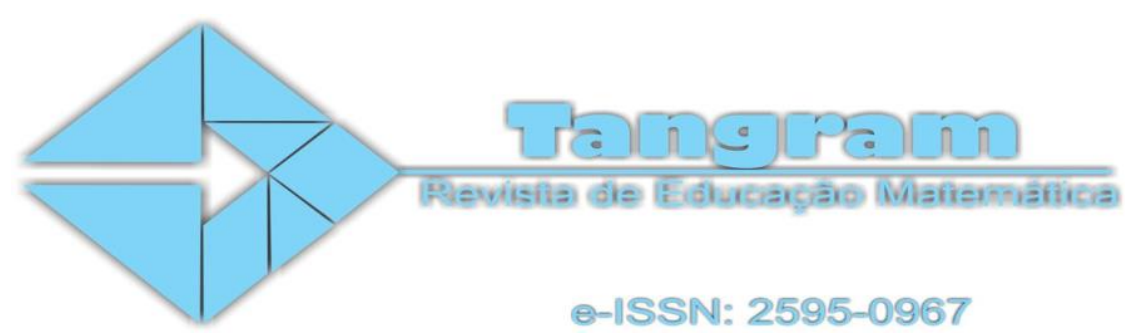

consistiu na aula expositiva com a utilização de materiais recicláveis para auxiliar nas construções das circunferências. Além disso, foi possível notar que a resolução de situaçõesproblema se trata de uma abordagem que ele utiliza em suas aulas.

Vale salientar que a resolução de situações-problema é vista como uma das finalidades do ensino de Matemática. Em relação a essa forma de trabalhar os conteúdos matemáticos, alguns documentos oficiais, Base Nacional Comum Curricular (2018) e Orientações Curriculares para o Ensino Médio (2006), ressaltam que os estudantes do Ensino Médio são capazes de criar estratégias para resolver problemas matemáticos, em diferentes contextos e situações, e que isso o possibilitando ser o construtor do seu próprio conhecimento, permitindo encontrar aplicações dos conteúdos matemáticos em diversas situações do cotidiano.

\section{Planejamento}

Na reunião com o professor supervisor, realizada anteriormente as observações, ele disponibilizou o seu plano de curso. Este é um documento elaborado pelo docente e que apresenta os objetivos, conteúdos, metodologias e procedimentos que serão utilizados durante o ano letivo. $\mathrm{O}$ planejamento do estágio foi feito com base nesse documento.

Construímos um projeto de intervenção pedagógica, para nortear as atividades realizadas durante o estágio, e nessa proposta estava previsto a realização da docência durante a primeira unidade do ano letivo. Porém, devido à greve das universidades estaduais baianas o estágio foi interrompido, retornando mais de dois meses depois.

O planejamento, como afirma Luckesi (1992, p.121), é "um conjunto de ações coordenadas visando atingir os resultados previstos de forma mais eficiente". Para Vasconcellos (2014, p. 35) "planejar é antecipar mentalmente uma ação a ser realizada, é agir de acordo com o previsto". É, também, como salientam os autores, algo flexível que pode sofrer mudanças durante o processo. Dessa forma, todas as atividades ou ações

Tangram - Revista de Educação Matemática, Dourados - MS - v.3 n.3, pp. 162 - 177 (2020) Este obra está licenciada com uma Licença Creative Commons Atribuição-NãoComercial-CompartilhaIgual 3.0 Brasil. 


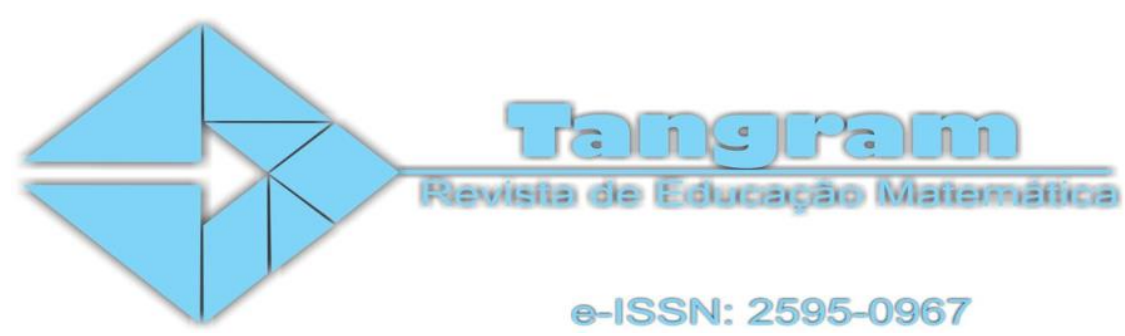

previstas na readequação da proposta foram (re)discutidas, tanto com o docente da unidade escolar, quanto com o professor orientador na Universidade.

O contato entre estagiário e planejamento escolar é importante, visto que se trata de um instrumento fundamental para alcançar resultados satisfatórios, pois minimiza as chances de erro no decorrer do processo de ensino aprendizagem ou, pelo menos, o prepara para antecipar algumas situações e contribui no saber lidar com elas (Silva, Souza, Barros e Almeida, 2014).

Diante disso, planejamos trabalhar os seguintes conteúdos: Matrizes, Determinantes e Sistemas lineares. Vale ressaltar que esses conteúdos, geralmente, são abordados no segundo ano do Ensino Médio, no entanto estavam previsto para ser trabalhados com os alunos do terceiro ano, pois o docente que lecionava a disciplina de Matemática no ano anterior não trabalhou os referidos conteúdos, como nos informou o professor supervisor.

De acordo com Vasconcellos (2014, p. 35), "planejar ajuda concretizar aquilo que se almeja". Portanto, almejamos com a proposta de trabalho, desenvolvida no período do estágio, facilitar a aprendizagem dos conteúdos matemáticos que foram trabalhados durante a unidade, por meio de estratégias como a contextualização, resolução de situaçõesproblema, conexões entre conteúdos e utilização de recursos tecnológicos, de modo a proporcionar o conhecimento matemático de maneira significativa, pois quando não são evidenciadas as relações entre os assuntos, a Matemática é apresentada de forma estanque e o conhecimento é adquirido de maneira fragmentada. Por mais que seja abordada dessa forma no ambiente educacional, vale ressaltar que os conteúdos matemáticos estão interligados e é importante que os alunos se deparem com essas articulações.

Com relação à forma de avaliação, consideramos a participação no decorrer das aulas, o envolvimento durante a realização das atividades, bem como o desempenho nas atividades avaliativas escritas. Além disso, conforme a proposta feita no início do estágio, os instrumentos avaliativos foram: a) atividades composta por situações-problema referentes

Tangram - Revista de Educação Matemática, Dourados - MS - v.3 n.3, pp. 162 - 177 (2020) 


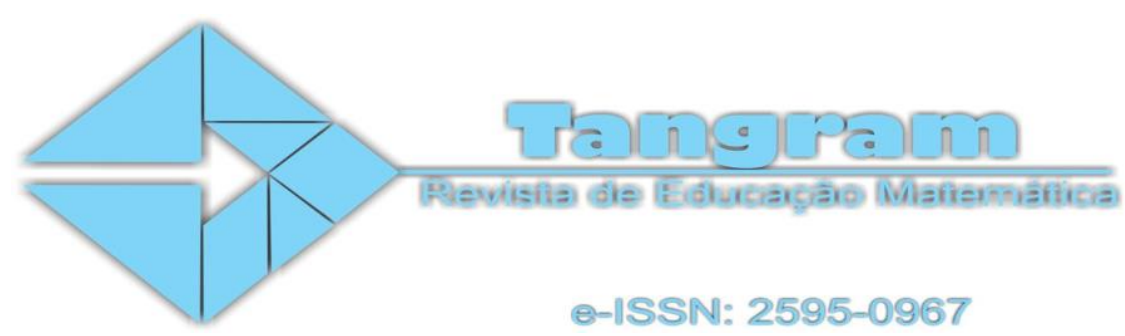

aos conteúdos trabalhados; b) atividades realizadas dentro da sala de aula e c) exercícios compostos por questões de vestibulares e do ENEM.

\section{Docência}

Após o período de observação e planejamento da proposta de trabalho, iniciou-se a docência. No primeiro momento, conversamos com os alunos acerca da proposta de trabalho que seria adotada a partir daquele momento. Em seguida, dando continuidade ao conteúdo que o professor supervisor estava trabalhando, abordamos os conceitos de Arcos congruentes.

Como os arcos possuem a mesma extremidade e diferenciam-se apenas pelo número de voltas, estabelecemos, para realizar o trabalho em sala de aula, a relação com manobras da modalidade esportiva "Skate". Como exemplo, apresentamos o movimento chamado de “900”, que acontece quando o skatista parte de um ponto, dá duas voltas e meia no ar e termina a manobra no lado oposto de onde partiu. Grande parte da turma já tinha ouvido falar sobre esse movimento e alguns alunos sinalizaram que praticam essa modalidade esportiva. Dessa forma, o exemplo citado foi interessante, uma vez que serviu para mostrar a relação do conteúdo trabalhado no cotidiano desses estudantes.

Durante o período de regência, quando possível, foram criadas situações presentes no contexto social dos alunos para que os mesmo pudessem entender e perceber no cotidiano a utilidade dos conteúdos que foram trabalhados. Quando os assuntos são abordados e o professor estabelece a relação com o contexto social, "ajuda a desenvolver no aluno a capacidade de relacionar o aprendido com o observado e a teoria com suas consequências e aplicações práticas” (Dante, 2016, p. 276). Isto porque atribui significado ao que está sendo aprendido.

A contextualização dos conteúdos é uma importante estratégia para trabalhar os conteúdos matemáticos, pois segundo Costa e Allevato (2015, p. 03, apud NCTM, 1995, p. 34) "quando os alunos aprendem conceitos matemáticos isolados de um contexto, depressa

Tangram - Revista de Educação Matemática, Dourados - MS - v.3 n.3, pp. 162 - 177 (2020) 


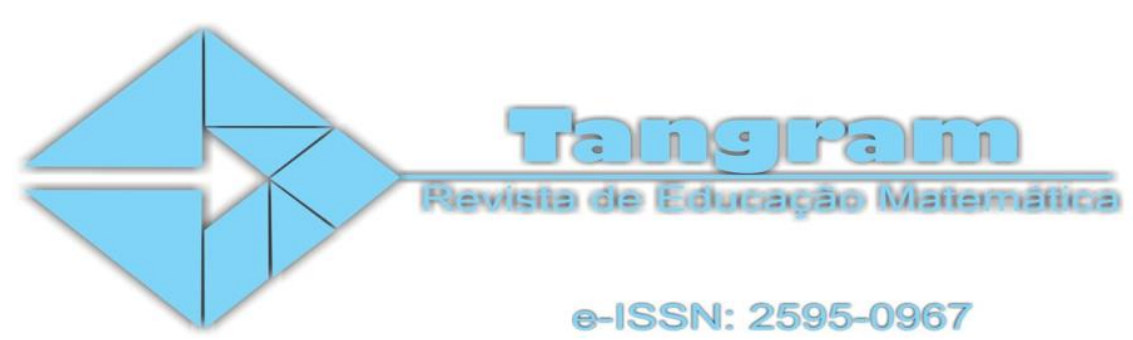

esquecem o seu significado. Quando aprendem Matemática ligada a situações do mundo real, ficam aptos a reconhecer e aplicar os conceitos em novas situações".

Além da abordagem utilizada para contextualizar o conteúdo, trabalhou-se exercícios diversos. Nestes os alunos calcularam os arcos côngruos em graus e radianos das questões propostas, bem como a expressão geral referente a cada uma das questões.

Contudo, após a primeira semana de atividades de regência o estágio foi interrompido pela greve dos professores das universidades estaduais baianas que durou mais de dois meses. Durante esse período o professor supervisor trabalhou os conteúdos de trigonometria.

Assim, retomamos a regência com o conteúdo de matrizes, onde foram trabalhados os tipos, características e operações. Nesta etapa, notamos que parte dos alunos apresentavam dificuldades em conceitos básicos da Matemática, como por exemplo, as operações entre números inteiros. Com intuito de amenizar essa dificuldade, procuramos associar essas operações ao conceito de saldo e dívida. Essa estratégia contribuiu para os alunos resolverem de maneira correta as operações de soma e subtração de números inteiros.

Dessa forma, os discentes conseguiram aprender as operações de soma e subtração de matrizes de maneira mais rápida. Porém, ao abordar a operação de multiplicação do referido conteúdo, a maioria apresentou dificuldades. Diante disso, utilizou-se da resolução de exercícios e situações-problema para que eles entendessem os conceitos e as estratégias de resolução.

Vale ressaltar que as matrizes são tabelas retangulares utilizadas para organizar dados numéricos. Porém, como salienta Dante (2016), essa forma de representar conjuntos numéricos apareceu no século XIX, embora haja evidencias de que os chineses já resolvessem problemas, por meio desse conteúdo muito antes disso.

Esse assunto possui importantes aplicações dentro da informática, por exemplo, nas planilhas eletrônicas, onde são organizadas as informações em forma de matriz para facilitar a realização de cálculos. Quando uma pessoa tira uma foto no celular e rotaciona para ficar numa melhor posição de visualização, ela está utilizando de uma das aplicações, visto que

Tangram - Revista de Educação Matemática, Dourados - MS - v.3 n.3, pp. 162 - 177 (2020) 


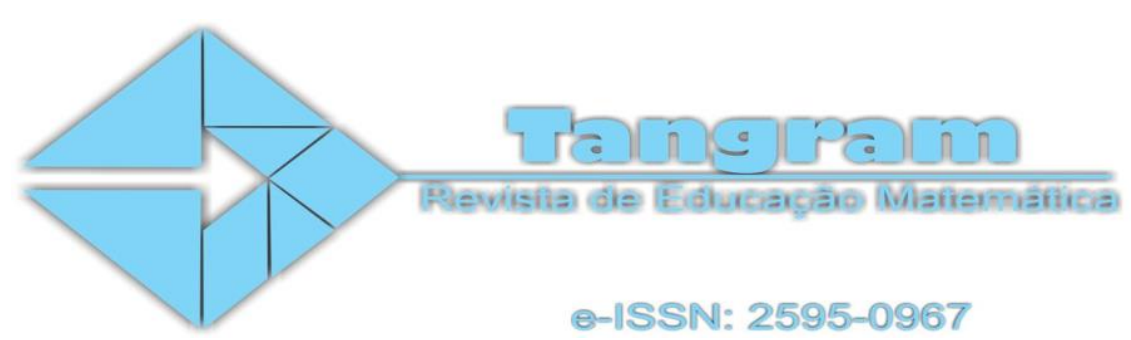

esse processo de rotação é feito por meio de operações de matrizes, além disso, a criptografia de mensagens pode ser feita através desse conteúdo.

Diante do mundo em que vivemos, são inegáveis os avanços e os impactos provocados pela tecnologia da informação e comunicação na sociedade atual. Conforme Pacheco, Pinto e Petroski (2015) é possível perceber que os alunos estão, a todo o momento, conectados aos instrumentos tecnológicos, tanto que muitos deles não estão copiando os conteúdos que são explicados no quadro, pelo professor; simplesmente tiram fotos.

Isso evidencia a necessidade de o professor procurar formações continuadas que o prepare para o uso pedagógico dos recursos tecnológicos. Para isso, é preciso que o docente busque alternativas para ressignificar a forma como são trabalhados os conteúdos, pois pode se utilizar dessa tecnologia como uma forma para subsidiar a aprendizagem não só da Matemática, mas de todas as outras disciplinas presentes no currículo escolar.

Nessa perspectiva, as orientações curriculares para o Ensino Médio ratificam que "é importante contemplar uma formação escolar nesses dois sentidos, ou seja, a Matemática como ferramenta para entender a tecnologia, e a tecnologia como ferramenta para entender a Matemática" (Orientações Curriculares para o Ensino Médio, 2006, p. 87).

Diante disso, os softwares matemáticos são ferramentas tecnológicas que os docentes podem utilizar em suas aulas como instrumentos para entender conceitos matemáticos, bem como para os alunos fazerem experimentos e criarem estratégias a fim de resolver problemas.

Dando continuidade ao estudo das matrizes, abordou-se o conceito de Determinantes, as características e estratégias para o seu cálculo. Esse foi o último conteúdo trabalhado na segunda unidade. Notou-se que a maioria dos discentes conseguiu um bom desempenho na atividade.

Dessa forma, no início da terceira unidade, trabalhamos o conteúdo de Sistemas lineares, onde foi abordado o conceito de Equações lineares, Matriz de um sistema linear, Regra de Cramer e discussão de Sistemas. Com o intuito de proporcionar uma melhor

Tangram - Revista de Educação Matemática, Dourados - MS - v.3 n.3, pp. 162 - 177 (2020) 


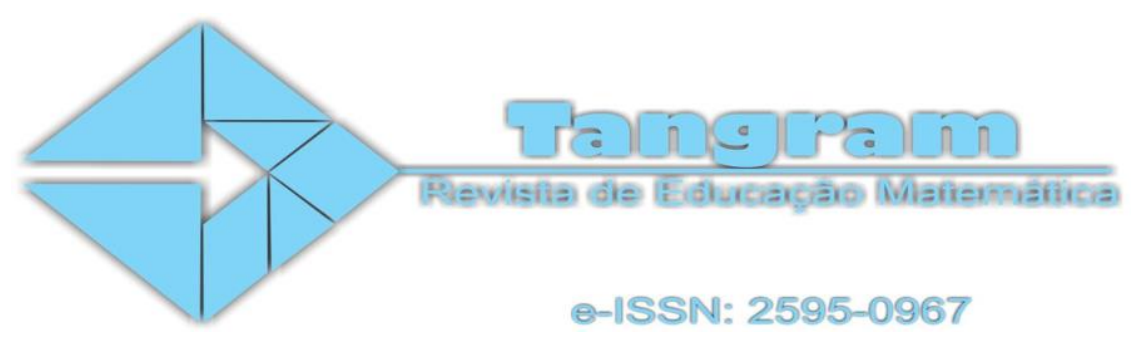

aprendizagem e tornar as aulas mais atrativas, usou-se do software matemático denominado Geogebra para discussão e análise dos três tipos de sistemas lineares de ordem $2 \times 2$. O sistema linear possível determinado, possível e indeterminado e impossível. Essa discussão foi feita a partir da análise geométrica, associando ao estudo da posição relativa de duas retas no plano cartesiano e relacionado com o conteúdo de função afim, estudado no primeiro ano do Ensino Médio.

$\mathrm{O}$ assunto foi evidenciado dessa maneira, pois acreditamos que estabelecer, durante as aulas, essas conexões existentes entre os conteúdos pode proporcionar uma aprendizagem significativa, fazendo com que os estudantes percebam que os conceitos matemáticos estão interligados, por mais que alguns conteúdos estejam organizados separadamente em unidade temáticas (Santos e Vieira, 2019).

Tendo em vista que fazer aula não é somente expor o conteúdo, Ponte (2002) destaca que não basta ao docente conhecer teorias, é preciso ter a capacidade de mobilizar e articular os diferentes conhecimentos as diferentes realidades escolares. Sendo assim, ao ensinar os conteúdos matemáticos, não basta trabalhar os mesmos de forma isolada, é importante estabelecer as relações e as conexões entre eles, para que os alunos possam adquirir por meio dessa articulação um conhecimento profundo e diversificado. Esse movimento, para nós estagiários, permite desenvolver o que Shulman (2005) apresenta como conhecimento didático do conteúdo.

Quando os alunos percebem que os conteúdos matemáticos então entrelaçados, isto é, quando o professor trabalha os conteúdos e mostra as relações existentes entre eles, isso pode melhorar o interesse pela disciplina. Dessa forma, Costa e Allevato (2015, p. 03) evidenciam que "a compreensão das conexões dentro e entre os conteúdos matemáticos faz com que as dificuldades encontradas pelos alunos em compreender a Matemática escolar sejam minimizadas".

No entanto, muitas vezes, é necessário que o professor utilize do conhecimento prévio que os alunos dispõem e também de suas experiências pessoais, para realizar

Tangram - Revista de Educação Matemática, Dourados - MS - v.3 n.3, pp. 162 - 177 (2020) 


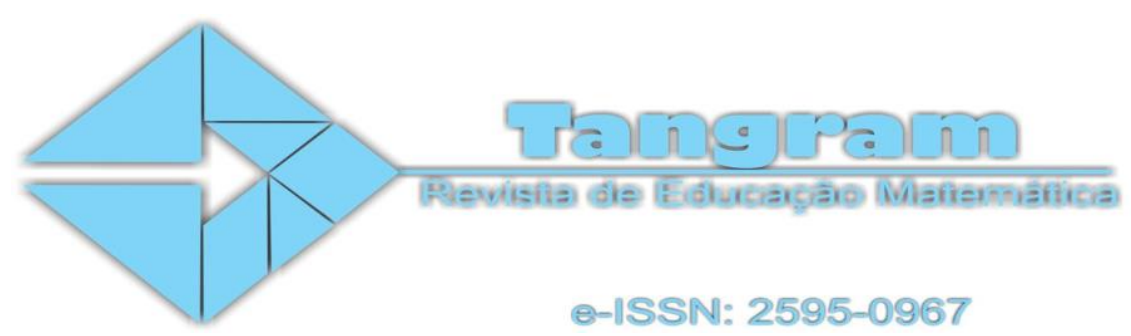

conexões entre os conteúdos. O docente pode criar situações que estão presentes no cotidiano dos alunos ou no próprio contexto da Matemática, estimulando a curiosidade, criatividade e mostrando significado e aplicações para os conteúdos matemáticos. Portanto, é importante ressaltar que os alunos devem ser agentes ativos nesse processo, capazes de produzir o seu próprio conhecimento.

\section{Oficina: criptografia e matrizes}

Para finalizar a regência, vivenciamos uma oficina pedagógica sobre o conteúdo de Matrizes. Essa atividade teve como objetivo apresentar a criptografia de mensagens como uma das aplicações do conteúdo, de modo que os estudantes aprendessem a utilizar essa técnica de comunicação segura que está presente em diversos dispositivos do cotidiano.

A criptografia é um conjunto de procedimentos que possibilita escrever uma mensagem em código, de modo que somente o emissor e o destinatário permitido sejam capazes de decodificá-la. Este método já era utilizado desde a Antiguidade, pois era necessário guardar mensagens secretas, onde somente algumas pessoas podiam interpretálas (Pereira et al., 2016).

As atividades propostas pela oficina foram constituídas da seguinte maneira:

Primeiramente, apresentamos uma mensagem codificada e explicamos como se constitui o processo para decifrá-la utilizando matrizes. A turma foi dividida em dois grupos. Na sequência, cada grupo criou sua própria mensagem criptografada e trocou a outra equipe. O desafio era tentar decifrar a mensagem escrita sabendo a matriz chave que usaram.

Vale ressaltar que, anteriormente à apresentação dos conceitos sobre criptografia de mensagens com a utilização de matrizes, foi trabalhado com os alunos o conceito de matriz inversa, através de aula expositiva. Essa abordagem teve como objetivo reforçar a operação de multiplicação de matrizes e discutir sobre as matrizes invertíveis, uma vez que esses assuntos foram pré-requisitos para aplicação da oficina.

Tangram - Revista de Educação Matemática, Dourados - MS - v.3 n.3, pp. 162 - 177 (2020)

Este obra está licenciada com uma Licença Creative Commons Atribuição-NãoComercial-CompartilhaIgual 3.0 Brasil. 


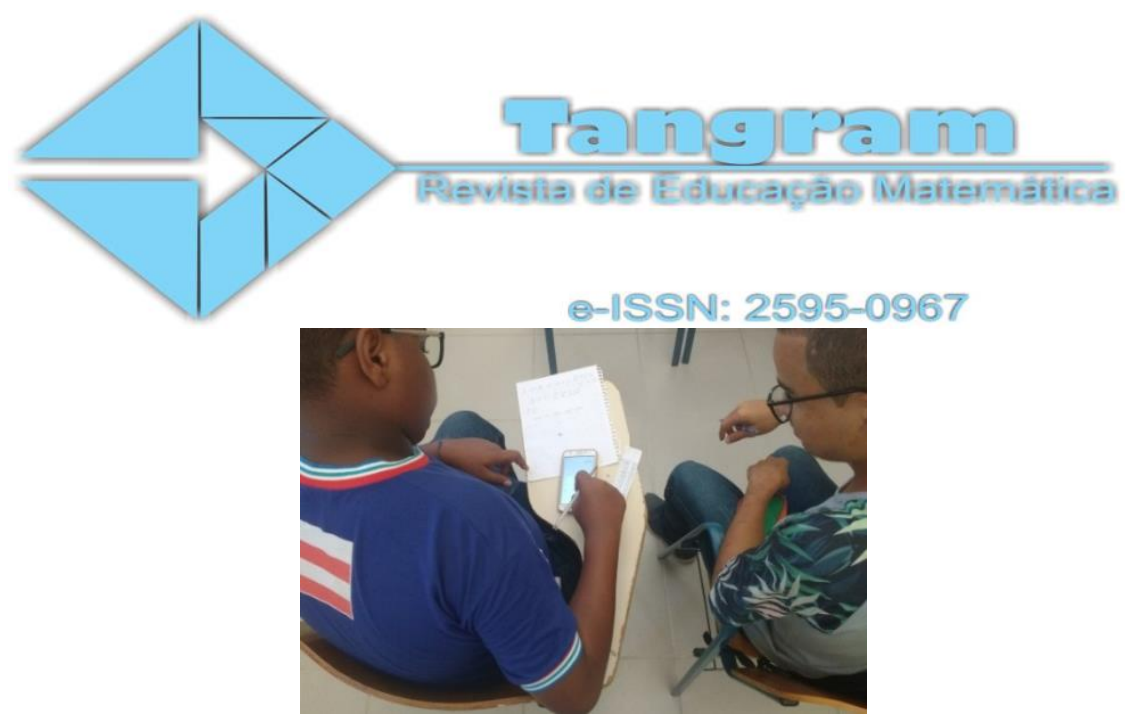

Imagem 01 - Grupo decodificando a mensagem Fonte: arquivo pessoal dos autores

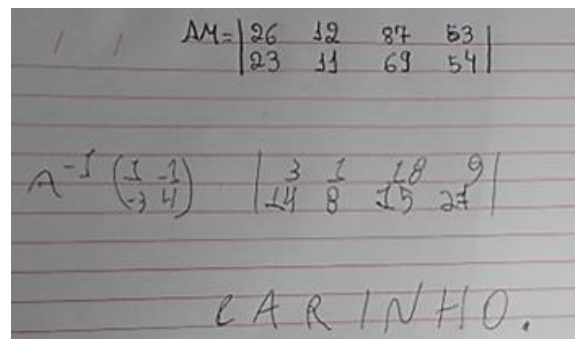

Imagem 02 - mensagem decodificada pelo grupo Fonte: arquivo pessoal dos autores

Dentre vários pontos positivos que podem ser destacados no decorrer do processo de vivência da oficina, evidenciamos o empenho dos estudantes no desenvolvimento das atividades. Portanto, existem novas e diferentes formas de trabalhar os conteúdos que podem resultar em uma melhora na qualidade do ensino na Educação Básica. Cabe aos professores pesquisar, planejar e desenvolver atividades que despertem o interesse dos estudantes pelos conteúdos matemáticos.

\section{Considerações Finais}

É indiscutível a importância do Estágio Curricular Supervisionado na formação do futuro professor de Matemática. Lidar com a rejeição de grade parte dos alunos, enfrentar o medo de assumir uma sala de aula como docente, tentar articular os diferentes conhecimentos necessários à docência desenvolvidos ao longo do curso de licenciatura e das

Tangram - Revista de Educação Matemática, Dourados - MS - v.3 n.3, pp. 162 - 177 (2020) 


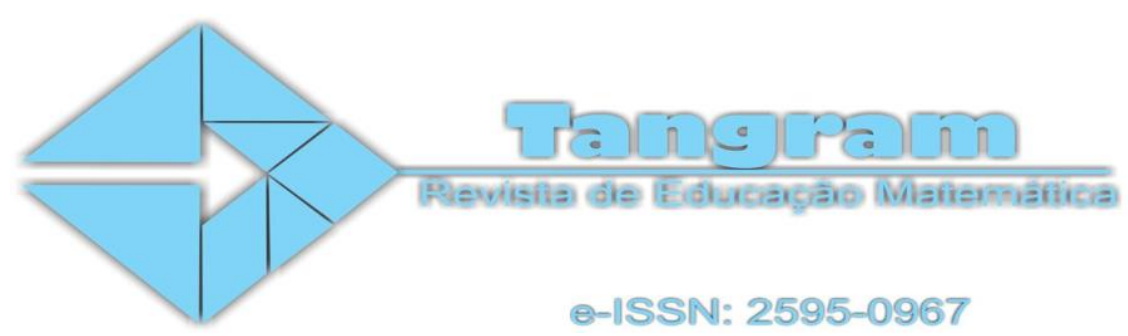

experiências com a sala de aula durante os quatro estágios, são algumas situações desafiadoras que, a priori, parecem impossíveis de serem solucionadas. No entanto, são esses e outros desafios que fazem com que o estagiário refletia e tente buscar novas estratégias de ensino para garantir uma melhor aprendizagem para os estudantes.

O planejamento, nesse percurso, é algo essencial no processo de ensino, além de ser uma maneira de prever algumas situações a fim de desenvolver o melhor trabalho possível; facilita a tomadas de decisões e diminui as chances de erro no decorrer do processo; quando não há planejamento as chances de alcançar resultados insatisfatórios são maiores.

As atividades desenvolvidas durante o Estagio Curricular Supervisionado IV proporcionaram reflexões sobre a forma como são trabalhados os conteúdos matemáticos. Quando os alunos se deparam com abordagens metodológicas que evidenciam a relação dos conteúdos com o seu cotidiano a aprendizagem matemática é mais eficiente.

Diante da realidade da sala de aula, é necessário que o docente coloque os "pés no chão", planeje e sempre procure alternativas para facilitar a aprendizagem para os alunos. Portanto, sempre irão existir desafios, cabe aos professores encontrar a melhor maneira para superá-los.

\section{Referências}

Base Nacional Comum Curricular. (2018). Ministério da Educação. Brasília. Recuperado em 01 julho, 2020, de http://basenacionalcomum.mec.gov.br/.

Orientações Curriculares para o Ensino Médio. (2006). Brasília. Recuperado em 01 julho, 2020, de http://portal.mec.gov.br/seb/arquivos/pdf/book_volume_02_internet.pdf.

Costa, M. S.; Allevato, N. S. G. (2015). Proporcionalidade e função afim: uma possível conexão através da resolução de problemas. XIV Conferência Interamericana de Educação Matemática. Chiapas, México.

Dante, L. R. (2016). Matemática: contexto e aplicações: Ensino Médio (3a ed). São Paulo: Ática.

Tangram - Revista de Educação Matemática, Dourados - MS - v.3 n.3, pp. 162 - 177 (2020)

Este obra está licenciada com uma Licença Creative Commons Atribuição-NãoComercial-CompartilhaIgual 3.0 Brasil. 


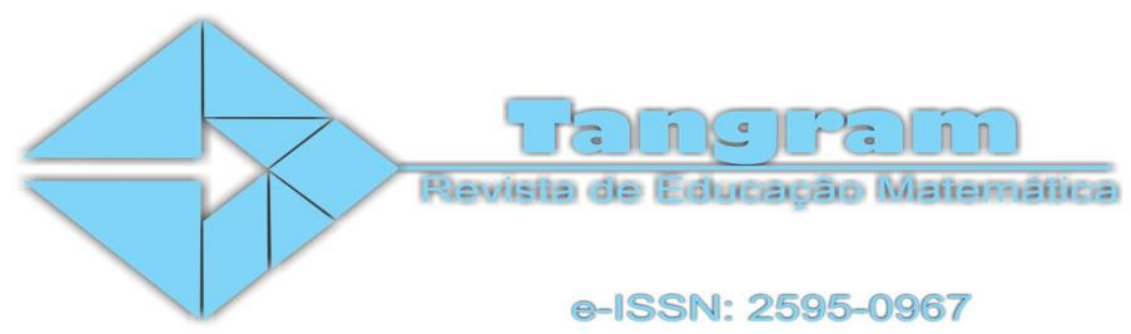

Gatti, B. (2010). Formação de professores no Brasil: características e problemas. Educação e Sociedade, 31 (113), pp. 1355-1379. Recuperado em 01 julho, 2020, de https://www.scielo.br/pdf/es/v31n113/16.pdf.

Gatti, B. A. Barreto, E. S. S. André, M. E. D. A. Almeida, P. C. A. (2019). Professores do Brasil: novos cenários de formação. Brasília: UNESCO.

Luckesi, C. C. (1997). Avaliação da aprendizagem Escolar, (6a ed). São Paulo: Cortez.

Pacheco, M. A. T. Pinto, L. R. Petroski, F. B. (2015). O uso do celular como ferramenta pedagógica: uma experiência válida. XIII Congresso Nacional de Educação Recuperado em 01 julho, 2020, de https://educere.bruc.com.br/arquivo/pdf2017/24549_12672.pdf.

Pereira, E. E. Souza, G. B. Cunha, R. G. Silva, V. S. F. Esteves, F. G. Pereira, P. C. S. (2016). Criptografia de dados utilizando matrizes. Revista Unifenas. 11 (1), pp. 1-9, Recuperado em 01 julho, 2020, de http://revistas.unifenas.br/index.php/RE3C/article/view/100/64.

Pimenta, S. G.; Lima, M. S. L. (2006). Estágio e docência: diferentes concepções. Revista Poíesis, 3 (3), pp. 5-24, Recuperado em 01 julho, 2020, de https://www.revistas.ufg.br/poiesis/article/view/10542.

Pimenta, Selma Garrido. (2004). Estágio e docência. São Paulo: Cortez.

Ponte, J. P. (2002). A vertente profissional da formação inicial de professores de Matemática. Educação Matemática em Revista. 9 (11), pp. 3-8, Recuperado em 01 julho, 2020, de http://www.educ.fc.ul.pt/docentes/jponte/docs-pt/02Ponte\%20(SBEM).pdf

Santos, G. L.; Vieira, A. R. L. (2019). Conexões entre conteúdos matemáticos: perspectiva para uma aprendizagem significativa. XIII Encontro Nacional de Educação Matemática. Recuperado em 01 julho, 2020, de https://www.sbemmatogrosso.com.br/eventos/index.php/enem/2019/paper/view/215 $\underline{3}$

Scalabrin, I. C.; Milionari, A. M. C. (2013). A importância da prática do estágio supervisionado nas licenciaturas. Revista Unar, 7 (1), pp. 1-12, Recuperado em 01 julho, 2020, de http://revistaunar.com.br/cientifica/documentos/vol7_n1_2013/3_a_importancia_da pratica_estagio.pdf

Tangram - Revista de Educação Matemática, Dourados - MS - v.3 n.3, pp. 162 - 177 (2020) 


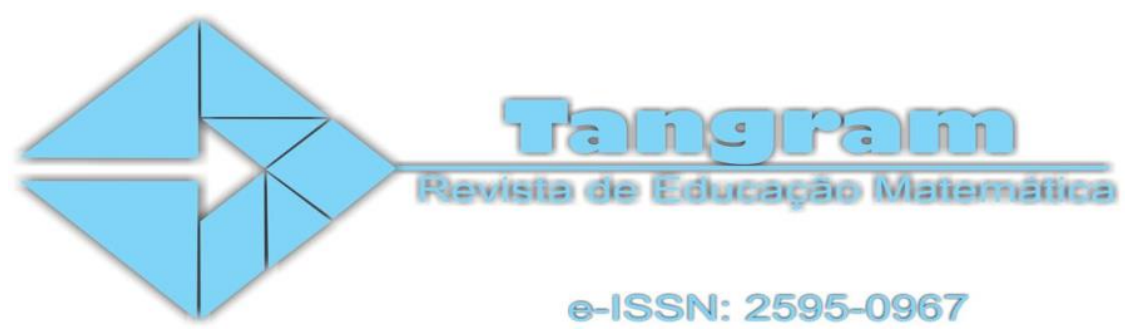

Silva, A. J. N. Souza, I. S. Barros, S. S. ALMEIDA, J. (2014) O professor de Matemática e o Ato de Planejar: Há Unicidade entre dimensão política e dimensão pedagógica. Jundiaí: Paco Editorial.

Shulman, L. S. (2005). Conocimiento y enseñanza: fundamentos de la nueva reforma. Profesorado. Revista de Currículum y formación del profesorado, 9 (2), pp. 1-30, Recuperado em 01 julho, 2020, de https://www.ugr.es/ recfpro/rev92ART1.pdf

Vasconcellos, C. S. (2014). Planejamento: projeto de ensino-aprendizagem e projeto político-pedagógico. São Paulo: Libertad Editora.

Zinke, I. A.; Gomes, D. (2015). A prática de observação e a sua importância na formação do professor de geografia. XII Congresso Nacional de Educação. Recuperado em 01 julho, 2020, de https://educere.bruc.com.br/arquivo/pdf2015/18655_7820.pdf.

Contribuições dos Autores

$1^{\text {a }}$ autor: conceitualização; curadoria de dados; análise formal; investigação; metodologia; administração do projeto; supervisão; visualização; redação - rascunho original; redação - revisão e edição.

$2^{\circ}$ autor: conceitualização; curadoria de dados; análise formal; investigação; metodologia; administração do projeto; supervisão; visualização; redação - rascunho original; redação - revisão e edição.

Tangram - Revista de Educação Matemática, Dourados - MS - v.3 n.3, pp. 162 - 177 (2020) 